\title{
Retirement of K. Shirley Smith as Editor
}

We begin the New Year on a regretful note. With the production of the December issue of the Journal, Kenneth Shirley Smith vacated the editorial chair which he had occupied since I959. He succeeded Maurice Campbell who had been Editor since the birth of the Journal in 1938. By the time Shirley Smith assumed office he was thoroughly familiar with the distinctive genre of the Journal which had been fashioned by Campbell and Evan Bedford who had shared editorial responsibilities for the first ten years. Bedford retired in 1948 and Campbell was left in sole charge. One of his first actions was to appoint Shirley Smith as Associate Editor. The choice was natural and successful. Shirley Smith was of scholarly inclination, and for the next decade collaborated happily with Campbell's demanding editorial requirements. He expressed his admiration and gratitude for Campbell's influence in an editorial tribute in the Journal, regarding him as the Journal's progenitor and formative influence.

In the 14 years of his reign, Shirley Smith continued the evolutionary process, imposing his strong and sensitive policies on the Journal's personality. He was firm in his rejection of ambiguity in expression and inaccuracy, in uncovering false claims to originality, in rating papers according to their scientific importance, and in maintaining an unimpeachable ethical standard. His artistic sensitivity was reflected in his concern for basic standards of presentation. He was never disturbed by the lack of a high literary style; a writer's way of expressing himself was his own business, but he was always required to make his meaning clear and with as few words as possible consistent with this objective. Otherwise Shirley Smith's only intrusion into an author's choice of words was his implacable distaste of certain prevalent clichés.

The liaison with the British Medical Association became closer in 1962 when Shirley Smith secured the appointment of Miss Rita Carne as Technical Editor. Her influence was immediately seen in textual accuracy and improved uniformity of production.

In recent years Shirley Smith had been uneasy about the physical appearance of the Journal. Yet any suggested change brought thunder from the back benches of the Cardiac Society whose servant is the Editor. However, the Editor acted in 1969, and the first issue of 1970 appeared in a new style. The crimson matt cover with obscure black type gave way to a stylish modern design, while, within, a new type and layout made reading easier, was more agreeable to the eye, and allowed figures and tables to be used to best advantage. These were Shirley Smith's concepts of a journal which now carried its message more efficiently in a more attractive vehicle.

The Journal flourished under Shirley Smith's guidance: in the course of 14 years the number of pages in each volume more than doubled, the Journal advanced to monthly publication (initially quarterly), and the circulation increased by more than 75 per cent. There is little to do in the immediate future except to keep to the present editorial course. Techniques of communication will change in time and we hope to play our proper part in evolving them. Meanwhile we regret Shirley Smith's leaving, are grateful for the prosperous order in which he left his charge, and wish him good fortune in the future.

WALTER SOMERVILIE 